\title{
An experimental investigation of the effects of chronic stress on bone-to-implant contact
}

\author{
Serkan Dundar', Alihan Bozoglan, Ferhan Yaman², Mustafa Kirtay ${ }^{3}$, Ozgur Bulmus ${ }^{4}$, \\ Hacer Sahin Aydinyurt ${ }^{5}$, Murat Yavuz Solmaz ${ }^{6}$, Cenk Yanen ${ }^{6}$ \\ ${ }^{I}$ Department of Periodontology, Faculty of Dentistry, Firat University, Elazig, ${ }^{2}$ Private Practice, Oral and Maxillofacial Surgeon, \\ Diyarbakir, Turkey, ${ }^{3}$ Private Practice, Oral and Maxillofacial Surgeon, Toronto, Canada, ${ }^{4}$ Department of Physiology, Faculty of \\ Medicine, Firat University, Elazig, ${ }^{5}$ Department of Periodontology, Faculty of Dentistry, Yüzüncü Yll University, Van, ${ }^{6}$ Department of \\ Mechanical Engineering, Faculty of Engineering, Firat University, Elazig, Turkey
}

\begin{abstract}
J Korean Assoc Oral Maxillofac Surg 2019;45:91-96)
Objectives: This study aimed to investigate the effects of chronic restraint stress on the osseointegration of titanium implants.

Materials and Methods: Twenty adult male Wistar albino rats were used in the study. After surgical insertion of titanium implants into the metaphyseal part of the tibial bone, rats were randomly divided into two groups: a control group (CNT group) and an experimental restraint stress group (RS group). In the CNT group, titanium implants were inserted surgically, and rats received no further treatment during the 47-day experimental period. In the RS group, restraint stress was applied for 3 hours per day for 45 days, beginning 2 days after implant surgery. Weight of the rats was measured prior to surgery and at the end of the study to analyze the effects of stress. At the end of the experimental period, rats were euthanized, and implants and surrounding bone tissues were used for undecalcified histological analysis. Serum cortisol levels were assessed in cardiac blood samples from the rats following centrifugation.

Results: Average weight of rats in the RS group was lower than that of rats in the CNT group after the experimental protocol had been completed $(P<0.05)$. Further, serum cortisol levels were higher in the RS group than in the CNT group $(P<0.05)$. There were no significant differences in boneimplant connection levels between the two groups $(P>0.05)$.
\end{abstract}

Conclusion: The data analyzed in this study suggest that chronic restraint stress did not adversely affect rats during a 45-day osseointegration period.

Key words: Restraint stress, Osseointegration, Bone-to-implant contact, Rats, Tibia

[paper submitted 2018. 5. 17 / revised 2018. 6. 29, / accepted 2018. 7. 2]

\section{Introduction}

Stress significantly affects a large part of the population worldwide, regardless of age, sex, or social class. The scientific community believes stress to be one of the most important risk factors for the onset of numerous diseases ${ }^{1-5}$. Indeed, chronic stress can negatively affect both physical and mental health. The impact of stress on the destruction of

\section{Serkan Dundar \\ Department of Periodontology, Faculty of Dentistry, Firat University, Campus, Elazig 23119, Turkey \\ TEL: +90-424-237-00-00/1746 FAX: +90-424-212-27-17 \\ E-mail:dtserkandundar@gmail.com \\ ORCID: https://orcid.org/0000-0003-3944-1957}

(c) This is an open-access article distributed under the terms of the Creative Commons Attribution Non-Commercial License (http://creativecommons.org/ licenses/by-nc/4.0/), which permits unrestricted non-commercial use, distribution, and reproduction in any medium, provided the original work is properly cited. Copyright (C) 2019 The Korean Association of Oral and Maxillofacial Surgeons. All rights reserved. periodontal tissues in rats has previously been investigated by a number of researchers ${ }^{1-5}$. Stress activates the hypothalamicpituitary-adrenal pathway and thereby increases the amount of corticotrophin-releasing hormone secreted by the hypothalamic paraventricular nucleus. This mechanism in turn stimulates the release of adrenal corticosteroids by stimulating the secretion of adrenocorticotropin from the anterior pituitary gland $^{6,7}$.

Wound healing is known to be affected by various conditions, including chronic and acute stress. Although the mechanisms that cause stress to disrupt the process of wound healing have not yet been fully elucidated, disruption may occur due to stress activating the hypothalamic-pituitaryadrenal axis. In addition, some experimental animal studies have reported that glucocorticoids delay soft-tissue wound healing and thereby adversely affect the bone-to-implant contact $(\mathrm{BIC})^{8-10}$. Dental implant-supported prostheses are a com- 
monly used and scientifically accepted treatment option for both partial and complete edentulism. However, the systemic condition of the patient, the quality of the bone into which the implant is placed, the shape and surface characteristics of the implant, as well as whether or not the patient is a smoker are all important factors that determine the success of dental implant therapy ${ }^{11-13}$. Although there is a growing body of evidence that chronic stress negatively affects wound healing, the effects of stress on the BIC have not yet been fully investigated in the literature and hence remain controversial ${ }^{14,15}$. Therefore, our aim in this study was to investigate the effects of chronic stress on the osseointegration of titanium implants in the tibial bones of rats.

\section{Materials and Methods}

\section{Animals and experimental design}

All experimental and surgical procedures involved in this study were conducted at the Firat University Experimental Research Center in Elazig, Turkey. Approval for the study was granted by the Firat University Animal Experimental Ethics Council (No. 2016/60). Further, the recommendations of the Declaration of Helsinki regarding the protection of laboratory research animals were stringently followed. In this study, 20 healthy adult male Wistar albino rats aged 1 to 1.2 years were used. On the first day of the experimental period, the average body weight of the rats was 400 to $440 \mathrm{~g}$. Rats were kept in plastic cages, and the temperature of the cages was checked daily. Throughout the experimental period, the rats had free access to food and water, and they experienced a cycle of 12 hours of dark and 12 hours of light.

Titanium implants were surgically inserted into the tibial bones of the rats. After the surgical procedure, rats were randomly divided into two groups with similar mean weights: a control group (CNT group) $(n=10)$ and an experimental restraint stress group (RS group) $(\mathrm{n}=10)$. In the $\mathrm{CNT}$ group, titanium implants were inserted surgically, and rats received no further treatment during the 47-day experimental period. In the RS group, titanium implants were also inserted surgically, and then restraint stress was applied for 3 hours per day throughout the 45-day experimental period, beginning 2 days after the implant surgery ${ }^{14,15}$.

\section{Surgical procedures}

Ketamine hydrochloride $(35 \mathrm{mg} / \mathrm{kg})$ and xylazine $(5 \mathrm{mg} /$ $\mathrm{kg}$ ) were intramuscularly injected into the rats to achieve general anesthesia. All surgical procedures were performed under sterile conditions. After the rats were anesthetized, the surgical site was washed with povidone iodine and then shaved. A 15-mm-long incision was made to the right tibial crest, the soft tissues were dissected and incised, and the tibial metaphyseal bone was exposed. Implant sockets were created using appropriate drill sizes (point drill, $1.2 \mathrm{~mm}, 1.8 \mathrm{~mm}$, and $2.2 \mathrm{~mm}$ diameter) with saline perfusion. Implants were then installed into the metaphyseal part of the tibial bone and primary stabilization was achieved. Titanium implants were 4 $\mathrm{mm}$ in length and $2.5 \mathrm{~mm}$ in diameter.(Fig. 1) Following the placement of the titanium implant, the flap was returned to the original position, and the fascia, subcutaneous tissue, and skin were sutured using 4-0 polyglactin sutures. To prevent pain and infection, an antibiotic (50 $\mathrm{mg} / \mathrm{kg}$ cefazolin sodium) and an analgesic $(0.1 \mathrm{mg} / \mathrm{kg}$ tramadol hydrochloride) were intramuscularly injected into all rats for 3 days following the surgical procedures. All surgical procedures were performed atraumatically by the same researcher. During the experimental period, three rats from the CNT group and three rats from the RS group died. Hence, the study was completed with seven rats in each group.

\section{Restrain stress application}

Restraint stress was applied to the rats in the RS group using special devices. Rats were placed in polyvinylchloride tubing according to their size, and holes were drilled in the tubes at the level of the rats' noses to allow them to breathe. This restraint procedure was performed for 3 hours per day throughout the experimental period ${ }^{14,15}$.

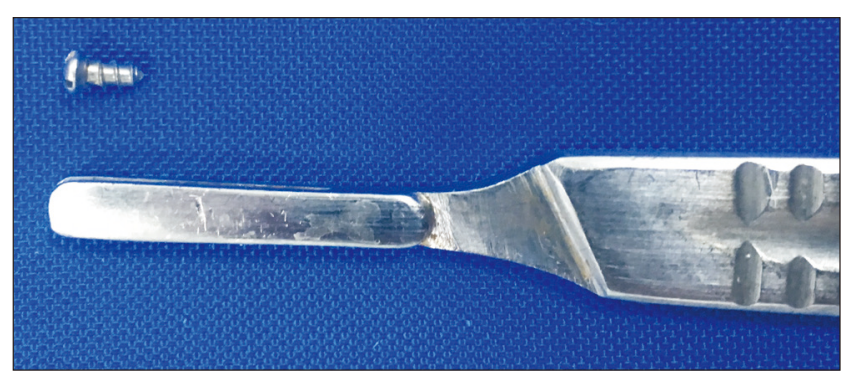

Fig. 1. Machined surfaced titanium implant installed in rat tibias. Serkan Dundar et al: An experimental investigation of the effects of chronic stress on bone-to-implant contact. J Korean Assoc Oral Maxillofac Surg 2019 


\section{Biochemical analysis}

Prior to sacrifice under general anesthesia, the final weight of each rat was measured. Then, blood samples were collected by means of cardiac puncture without anticoagulant to measure cortisol levels. Blood cortisol levels were measured for each rat in the biochemistry laboratory of Faculty of Medicine at Firat University ${ }^{14}$.

\section{Histological analysis}

After blood samples had been taken, titanium implants and the surrounding bones were stored in $10 \%$ formalin solution for histological analysis. These procedures were performed in the research laboratory of Faculty of Dentistry at University of Erciyes, Kayseri, Turkey. For histological analyses, specimens were embedded in 2-hydroxyetylmetacrylate resin to enable cutting of undecalcified bone and titanium using an Exakt microtome (Exakt Apparatebau, Norderstedt, Germany). For the histological BIC analyses, each section was ground using an Exakt grinder (Exakt Apparatebau), and a $50-\mu \mathrm{m}$-thick section was obtained for light microscopy analysis. Toluidine blue stain was used for all histological analyses. Following these procedures, further histological analyses were performed to quantify the bone tissue response in the peri-implant bone ${ }^{12,16,17}$. Histological analyses of BIC level were then performed using an image analyzer in the Department of Microbiology Laboratory, Faculty of Medicine, Firat University. The BIC level was defined as the ratio of the length of the implant surface directly touching the bone to the

Table 1. Day 1 and day 47 weight measurements of the two groups

\begin{tabular}{lrccc}
\hline \multicolumn{1}{c}{ Group } & Day & No. of rats & Weight $(\mathrm{g})$ & $P$-value \\
\hline Control & 1 & 10 & $417.40 \pm 8.88$ & 0.220 \\
Restraint stress & 47 & 7 & $427.14 \pm 6.74$ & \\
& 1 & 10 & $429.70 \pm 6.11$ & $<0.001$ \\
\hline
\end{tabular}

Values are presented as number only or mean \pm standard deviation. Serkan Dundar et al: An experimental investigation of the effects of chronic stress on bone-to-implant contact. J Korean Assoc Oral Maxillofac Surg 2019

Table 2. Cortisol levels of the groups at the end of the study

\begin{tabular}{lccc}
\hline \multicolumn{1}{c}{ Group } & No. of rats & $\begin{array}{c}\text { Cortisol level } \\
(\mu \mathrm{g} / \mathrm{dL})\end{array}$ & $P$-value \\
\hline Control & 7 & 0 & \\
Restraint stress & 7 & $0.33 \pm 0.31$ & 0.031 \\
\hline
\end{tabular}

Values are presented as number only or mean \pm standard deviation. Serkan Dundar et al: An experimental investigation of the effects of chronic stress on bone-to-implant contact. J Korean Assoc Oral Maxillofac Surg 2019 total length of the implant surface $\mathrm{e}^{12,16,17}$.

\section{Statistical analysis}

IBM SPSS Statistics 22.0 (IBM Corp., Armonk, NY, USA) was used for all statistical analyses in the present study. Mean value \pm standard deviation for each group were calculated. Student's t-test was used to analyze the data, and $P$-values $<0.05$ were considered to indicate statistical significance.

\section{Results}

During the period in which restraint stress was applied, rats in the CNT group exhibited an increase in body weight, while stressed animals (RS group) exhibited significant weight loss $(P<0.05)$. (Table 1)

In biochemical analysis of blood cortisol levels, those samples determined to be below $0.5 \mu \mathrm{g} / \mathrm{dL}$ were accepted to be 0 $\mu \mathrm{g} / \mathrm{dL}$. The detected cortisol level was significantly higher in the RS group than in the CNT group $(P<0.05)$. (Table 2)

After 47 days, there were no significant differences in BIC levels between the two groups. However, the mean level of $\mathrm{BIC}$ in the CNT group was numerically higher than that in the RS group $(P>0.05)$. (Table 3, Fig. 2, 3)

\section{Discussion}

Despite the lack of prior studies investigating the effects of stress on bone healing, the harmful effects of stress on soft-tissue wound healing are well established in the medical literature. A comprehensive search of medical literature databases revealed only a few studies concerning the relationship between osseointegration and chronic stress ${ }^{14,15}$. In the present study, we found that chronic stress, as applied by means of restriction, did not have any adverse effects on the osseointegration of titanium implants.

Siqueira et al. ${ }^{14}$ reported that chronic stress may impair osseointegration by affecting the initial phase of bone healing in the rat mandible. In their study, during the early stages of

Table 3. Bone-to-implant contact $(\mathrm{BIC})$ ratio of the groups at the end of the study

\begin{tabular}{lccc}
\hline \multicolumn{1}{c}{ Group } & No. of rats & BIC (\%) & $P$-value \\
\hline Control & 7 & $37.86 \pm 3.49$ & 0.164 \\
Restraint stress & 7 & $35.29 \pm 2.98$ & \\
\hline
\end{tabular}

Values are presented as number only or mean \pm standard deviation. Serkan Dundar et al: An experimental investigation of the effects of chronic stress on bone-to-implant contact. J Korean Assoc Oral Maxillofac Surg 2019 

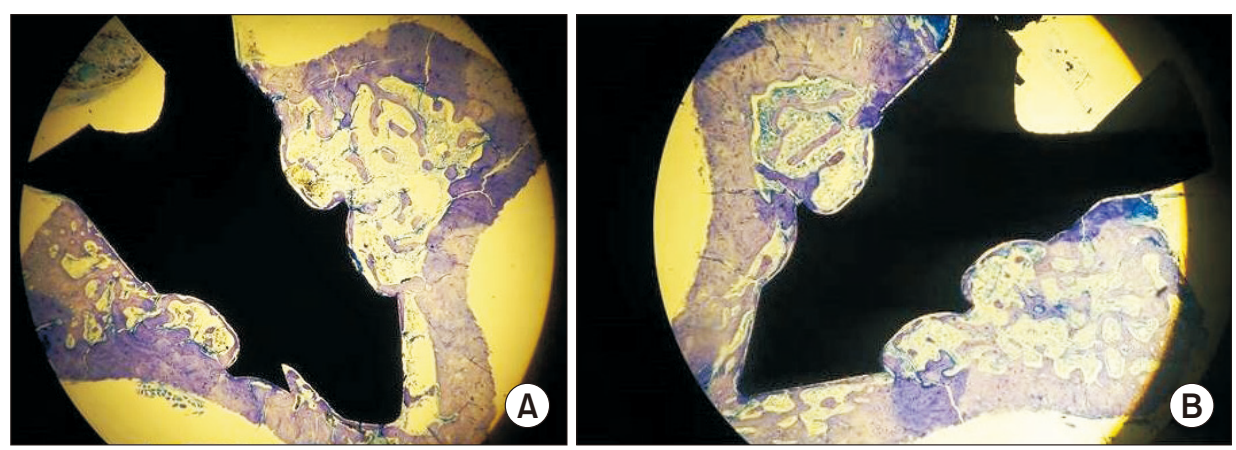

Fig. 2. Non-decalcified histologic images of the groups (toluidine blue staining, $\times 2$ ). (A) Control group. (B) Restraint stress group.

Serkan Dundar et al: An experimental investigation of the effects of chronic stress on bone-to-implant contact. J Korean Assoc Oral Maxillofac Surg 2019
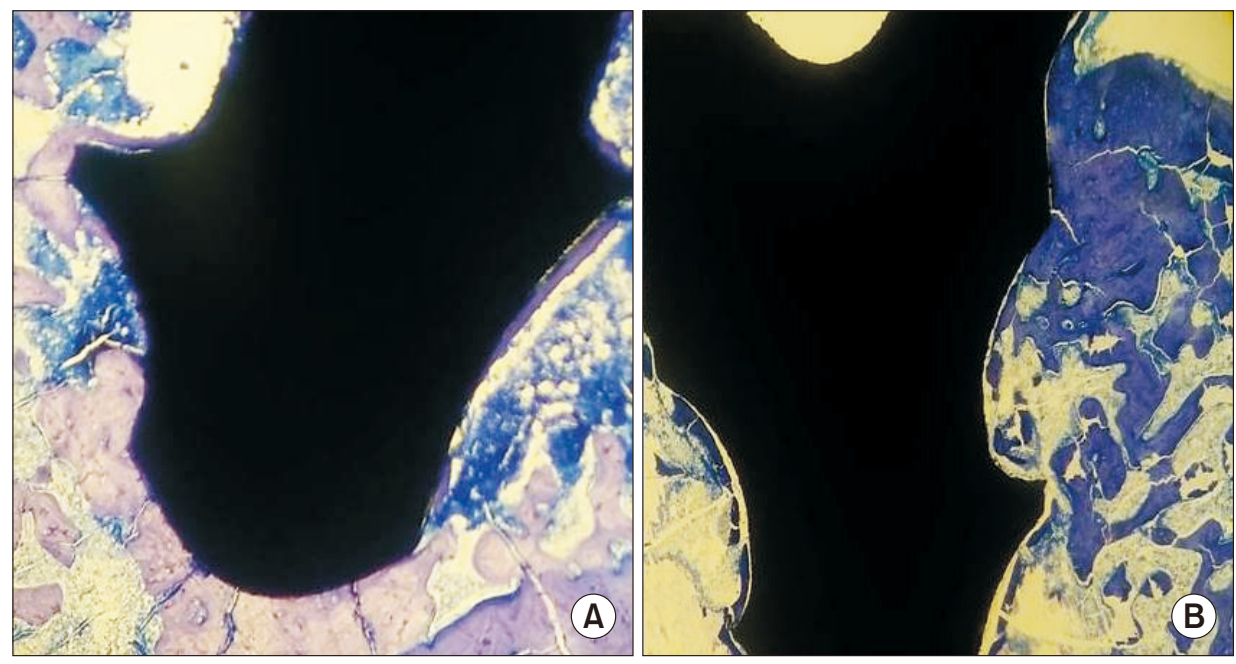

Fig. 3. Non-decalcified histologic images of the groups (toluidine blue staining, $\times 4$ ). (A) Control group. (B) Restraint stress group.

Serkan Dundar et al: An experimental investigation of the effects of chronic stress on bone-to-implant contact. J Korean Assoc Oral Maxillofac Surg 2019

bone healing, they detected less osseointegration of titanium implants in the stressed group than in the control group. Siqueira et al. ${ }^{14}$ further found that stress could inhibit the bone matrix and bone-forming cells, as well as the formation of collagenous fibers. They reported that 18 days of highintensity chronic stress destroyed the healing ability of immature tissues. At the end of the 18-day experimental period, the osseointegration level was significantly lower in the stressed group than in the control group ${ }^{14}$. However, there was no difference in osseointegration between the two groups at the end of the 33-day study period ${ }^{14}$. In a 28-day experimental osseointegration study, Conte Neto et al. ${ }^{15}$ detected an impairment in bone metabolism, as represented by low levels of bonespecific alkaline phosphatase and low bone area fraction occupancy values, in the chronic stress group. We examined the BIC level some 45 days after surgery was performed, and did not detect any statistically significant difference in BIC level between the two groups. The longer experimental period of our study than the above-mentioned studies may explain why we did not find a statistically significant difference in the BIC between the two investigated groups.

The pathophysiological relationship between stress and wound healing might be related to an increase in glucocorticoid levels. Cortisol is the most abundant glucocorticoid in rats, and it is thought to be a useful marker of rodents' stress levels ${ }^{12,18}$. In this study, the detection of high levels of plasma cortisol and lower body weights in stressed rats than control group rats indicates the importance of stress management. These results also show that, during the osseointegration period, rats in the experimental RS group did not adapt to the stress protocol ${ }^{12,15,18}$. Elevated cortisol levels can serve as physiological evidence of the presence of stress, and this study showed that the utilized experimental stress model increased the level of cortisol in the bloodstream of rats ${ }^{12,15,18}$. Stress can suppress or stimulate the immune system, and it also activates the hypothalamic-pituitary-adrenal pathway. Activation of this pathway results in the secretion of neuroendocrine and adrenal corticosteroid hormones, thereby rendering people susceptible to disease ${ }^{5,6,12,15,18}$. The immunoinflammatory response is a key contributor to periodontitis, peri-implantitis, and bone tissue health ${ }^{15,19,20}$.

Prior research concerning the relationship between bone tissue and stress has shown that the long-term administration of glucocorticoids increases osteoclast activity, suppresses 
osteoblastic activity, decreases bone mineral density, and is associated with the development of osteonecrosis ${ }^{12,15,21-23}$. Conte Neto et al. ${ }^{15}$ found that stressed rats in their experimental study exhibited more empty osteocyte lacunae areas than control rats. The association between glucocorticoids and osteonecrosis induction pathways may explain these findings ${ }^{21-23}$. However, the effects of experimental stress as initiated through the administration of exogenous steroids are thought to be different for two main reasons. First, stress can cause changes in behavioral responses and other physiological processes, including catecholamine release, which in turn reduces wound healing ${ }^{12,15,24}$. Second, the average potency of synthetic steroids is significantly lower than that of endogenous steroids, which means that the physiological effects of these hormones may also differ significantly in terms of their strength $^{25}$.

It is important to recognize that this study had a number of limitations. First, the molecular pathways underlying the relationship between chronic stress and the BIC could not be fully explored due to the methodology used in this study. Second, although animal studies are indispensable with regard to elucidating the mechanisms of stress-induced pathologies, estimates must then be made for humans based on the results obtained from animal models ${ }^{15}$. Third, we did not evaluate the implant survival rate or the long-term success of implants in this experimental study.

\section{Conclusion}

While acknowledging the limitations of this study, we found that chronic restraint stress did not affect the osseointegration of titanium implants in rats' tibial bones during a 45-day osseointegration period. Further studies are needed to clarify whether stress affects the osseointegration process associated with titanium implants.

\section{ORCID}

Serkan Dundar, https://orcid.org/0000-0003-3944-1957

Alihan Bozoglan, https://orcid.org/0000-0003-3420-5816

Ferhan Yaman, https://orcid.org/0000-0002-7583-2341

Mustafa Kirtay, https://orcid.org/0000-0003-2568-7470

Ozgur Bulmus, https://orcid.org/0000-0001-7736-402X

Hacer Sahin Aydinyurt, https://orcid.org/0000-0002-95219704

Murat Yavuz Solmaz, https://orcid.org/0000-0001-63940313
Cenk Yanen, https://orcid.org/0000-0002-5092-8734

\section{Authors' Contributions}

S.D., A.B., and F.Y. did the experimental phase of the study. S.D. wrote the manuscript and O.B., C.Y., and M.Y.S. checked the study. H.S.A. and M.K. helped the analysis.

\section{Acknowledgements}

The authors wish to thank BioInfinity Dental Implant System-Avrupa Dental Implant Corporation, Istanbul, Turkey for supporting non-decalcified histological analysis of the implants.

\section{Ethics Approval and Consent to Participate}

Approval for the study was granted by the Firat University Animal Experimental Ethics Council (No. 2016/60).

\section{Conflict of Interest}

No potential conflict of interest relevant to this article was reported.

\section{References}

1. Sapolsky RM. Stress, glucocorticoids, and damage to the nervous system: the current state of confusion. Stress 1996;1:1-19.

2. Takada T, Yoshinari N, Sugiishi S, Kawase H, Yamane T, Noguchi T. Effect of restraint stress on the progression of experimental periodontitis in rats. J Periodontol 2004;75:306-15.

3. Dyb G, Jensen TK, Nygaard E, Ekeberg O, Diseth TH, WentzelLarsen T, et al. Post-traumatic stress reactions in survivors of the 2011 massacre on Utøya Island, Norway. Br J Psychiatry 2014;204:361-7.

4. Semenoff-Segundo A, Porto AN, Semenoff TA, Cortelli JR, Costa FO, Cortelli SC, et al. Effects of two chronic stress models on ligature-induced periodontitis in Wistar rats. Arch Oral Biol 2012;57:66-72.

5. Rozanski A, Blumenthal JA, Davidson KW, Saab PG, Kubzansky L. The epidemiology, pathophysiology, and management of psychosocial risk factors in cardiac practice: the emerging field of behavioral cardiology. J Am Coll Cardiol 2005;45:637-51.

6. Dantzer R, Kelley KW. Stress and immunity: an integrated view of relationships between the brain and the immune system. Life Sci 1989;44:1995-2008.

7. Nakajima K, Hamada N, Takahashi Y, Sasaguri K, Tsukinoki K, Umemoto $\mathrm{T}$, et al. Restraint stress enhances alveolar bone loss in an experimental rat model. J Periodontal Res 2006;41:527-34.

8. Marucha PT, Kiecolt-Glaser JK, Favagehi M. Mucosal wound healing is impaired by examination stress. Psychosom Med 1998;60:362-5.

9. Padgett DA, Marucha PT, Sheridan JF. Restraint stress slows cutaneous wound healing in mice. Brain Behav Immun 1998;12:64-73. 
10. Carvas JS, Pereira RM, Caparbo VF, Fuller P, Silveira CA, Lima LA, et al. A single dose of zoledronic acid reverses the deleterious effects ofglucocorticoids on titanium implant osseointegration. Osteoporos Int 2010;21:1723-9.

11. Frisch E, Ziebolz D, Rinke S. Long-term results of implant-supported over-dentures retained by double crowns: a practice-based retrospective study after minimally 10 years follow-up. Clin Oral Implants Res 2013;24:1281-7.

12. Dundar S, Yaman F, Saybak A, Ozupek MF, Toy VE, Gul M, et al. Evaluation of effects of topical melatonin application on osseointegration of dental implant: an experimental study. J Oral Implantol 2016;42:386-9.

13. Correa MG, Gomes Campos ML, César-Neto JB, Casati MZ, Nociti FH, Sallum EA. Histometric evaluation of bone around titanium implants with different surface treatments in rats exposed to cigarette smoke inhalation. Clin Oral Implants Res 2009;20:58893.

14. Siqueira CR, Semenoff TA, Palma VC, Borges ÁH, Silva NF, Segundo AS. Effect of chronic stress on implant osseointegration into rat's mandible. Acta Cir Bras 2015;30:598-603.

15. Conte Neto N, de Andrade CR, Spolidorio LC, Planeta Cda S, Cruz FC, de Souza Bastos A, et al. Effects of chronic stress and alendronate therapy on the osseointegration of titanium implants. Clin Implant Dent Relat Res 2014;16:762-71.

16. Dündar S, Yaman F, Ozupek MF, Saybak A, Gul M, Asutay F, et al. The effects of high-fat diet on implant osseointegration: an experimental study. J Korean Assoc Oral Maxillofac Surg 2016;42:18792.

17. Dundar S, Yaman F, Gecor O, Cakmak O, Kirtay M, Yildirim TT, et al. Effects of local and systemic zoledronic acid application on titanium implant osseointegration: an experimental study conducted on two surface types. J Craniofac Surg 2017;28:935-8.

18. Park MH, Rehman SU, Kim IS, Choi MS, Yoo HH. Stress-induced changes of neurosteroid profiles in rat brain and plasma under immobilized condition. J Pharm Biomed Anal 2017;138:92-9.

19. Hasturk H, Kantarci A. Activation and resolution of periodontal inflammation and its systemic impact. Periodontol 2000 2015;69:255-73.

20. Kantarci A, Hasturk H, Van Dyke TE. Animal models for periodontal regeneration and peri-implant responses. Periodontol 2000 2015;68:66-82.

21. Chiu CT, Chiang WF, Chuang CY, Chang SW. Resolution of oral bisphosphonate and steroid-related osteonecrosis of the jaw--a serial case analysis. J Oral Maxillofac Surg 2010;68:1055-63.

22. Yamamoto T, Hirano K, Tsutsui H, Sugioka Y, Sueishi K. Corticosteroid enhances the experimental induction of osteonecrosis in rabbits with Shwartzman reaction. Clin Orthop Relat Res 1995;(316):235-43.

23. Weinstein RS. Glucocorticoids, osteocytes, and skeletal fragility: the role of bone vascularity. Bone 2010;46:564-70.

24. Romana-Souza B, Otranto M, Vieira AM, Filgueiras CC, Fierro IM, Monte-Alto-Costa A. Rotational stress-induced increase in epinephrine levels delays cutaneous wound healing in mice. Brain Behav Immun 2010;24:427-37.

25. Mahgoub A, Hirsch PF, Munson PL. Calcium-lowering action of glucocorticoids in adrenalectomized-parathyroidectomized rats. Specificity and relative potency of natural and synthetic glucocorticoids. Endocrine 1997;6:279-83. 